\title{
A green HPLC technique with a $100 \%$ water mobile phase for detecting imidacloprid and its metabolite 6-chloronicotinic acid
}

\author{
Naoto Furusawa*
}

Graduate School of Human Life Science, Osaka City University, Osaka 558-8585, Japan

\begin{tabular}{l} 
C H R O N I C L E \\
\hline Article history: \\
Received July 21, 2015 \\
Received in revised form \\
August 29, 2015 \\
Accepted 19 September 2015 \\
Available online \\
20 September 2015 \\
\hline Keywords: \\
International harmonized \\
analytical method \\
Imidacloprid \\
6-Chloronicotinic acid \\
100\% water mobile phase \\
HPLC \\
\hline
\end{tabular}

\begin{abstract}
A B S T R A C T
This paper describes a harmless HPLC technique for detecting imidacloprid (ICP) and its metabolite, 6-chloronicotinic acid (6CA), using an isocratic $100 \%$ water mobile phase. Chromatographic separations were performed a Daisopak ${ }^{\circledR}$ SP-200-3-C1-P with water mobile phase and a photodiode-array detector. The total run time was $<6$ min. The system suitability was well within the international acceptance criteria. The detection limits were $0.018 \mu \mathrm{g} / \mathrm{ml}$ for ICP and $0.005 \mu \mathrm{g} / \mathrm{ml}$ for 6CA, respectively. A harmless HPLC method for simultaneous detecting ICP and 6CA was developed and may be further applied to the quantification in animal-derived foods.
\end{abstract}

\section{Introduction}

Overuse of pesticides is always associated with risk of food residues. In December 2013, imidacloprid (1-(6-chloro-3-pyridylmethyl)-N-nitroimidazolidin-2-ylideneamine) (ICP) (Figure 1), a widely/frequently-used neonicotinoid insecticide, may affect the developing human nervous system, disclose the European Food Safety Authority. Experts from the authority propose that some guidance levels for acceptable exposure to ICP be lowered while further research is carried out to provide more reliable data on so-called developmental neurotoxicity. ${ }^{1}$

In pharmacokinetic findings of ICP in mammals, the two main metabolizing routes have been identified. The first is oxidative cleavage, yielding 6-chloronicotinic acid (6CA) (Fig. 1), which is conjugated with glycine to form a hippuric acid-type conjugate. These two metabolites together represented most of the identified metabolites. The metabolizing study in rats have found that the main * Corresponding author.

E-mail address: furusawa@life.osaka-cu.ac.jp (N. Furusawa) 
metabolites (about 30\%) were 6CA and its glycine conjugate; all other biotransformation products were quantitatively of minor significance. ${ }^{2}$<smiles>CCCCCCCC(C)(C)C(C)(C)C</smiles>

Fig. 1. Chemical structures of imidacloprid and its metabolite (6-Chloronicotinic acid)

To assure the safety of foods of animal origin for the consumer, the Codex sets maximum residue limits (MRLs) for the sum of ICP and its metabolites containing the 6-chloropyridinyl moiety, expressed as ICP. ${ }^{3}$ Because determinations for ICP together with 6CA in the animal foods are therefore an important specific activity to guarantee food safety, a validated analytical method for the simultaneous determining ICP and 6CA is presently required.

In response to the recent expansion and diversification in the international food trade, the development of international harmonized methods to determine chemical residues in foods is essential to guarantee equitable international trade in these foods and ensure food safety for consumers. Whether in industrial nations or developing countries, an international harmonized method for residue monitoring in foods is urgently-needed. The ideal harmonized method must be easy-to-use, economical in time and cost, and must cause no harm to the environment and analyst.

Previous techniques based on high-performance liquid chromatographic (HPLC) combined with UV, photo-diode array (PDA), MS, and MS/MS for the monitoring ICP and 6CA ${ }^{4-6}$ have crucial drawbacks: 1) all of the methods consume large quantities of toxic organic solvents, acetonitrile and/or methanol, ${ }^{7}$ in the mobile phases. Risk associated with these solvents extend beyond direct implications for the health of humans and wildlife to affect our environment and the ecosystem in which we all reside. Eliminating the use of toxic solvents and reagents is an important goal in terms of environmental conservation, human health and the economy; ${ }^{8,9}$ 2) most of the recent methods are based on LC-MS or -MS/MS. The facilities that LC-MS/MS system is available are limited to part of industrial nations because these are hugely expensive, and the methodologies use complex and specific. These are unavailable in a lot of laboratories for routine analysis, particularly in developing countries. No optimal method that satisfies the aforementioned requirements has yet been identified.

As the first examination problem in the establishment of an international harmonized method for the residue monitoring of ICP and 6CA, this paper describes an isocratic $100 \%$ water mobile phase HPLC conditions to detect ICP and 6CA.

\section{Results and Discussion}

\subsection{Optimum HPLC conditions}

Using five types of C1 columns (Table 1), the author tested to achieve the separation with a $100 \%$ water mobile phase. This study used water as an isocratic mobile phase and examined column temperatures $\geq 25^{\circ} \mathrm{C}$, the flow rates $\geq 0.75 \mathrm{ml} / \mathrm{min}$, and HPLC retention times $\leq 10 \mathrm{~min}$ (Table 1). Because the HPLC separations were performed serially, the time/run was critical for routine residue monitoring. The short run time not only increased sample throughout for analysis but also affected the method-development time. 
The five columns were compared with regard to 1) elution from the column; 2) separation between 6CA and ICP; 3) sharpness of peaks obtained upon injection of equal amounts. The chromatographic eluting and separating profiles within the conditions ranges examined are also presented in Table 1.

Under a 100\% water mobile phase, the complete elution/separation of the two compounds and their sharp peaks were obtained by a Column-(C) with column temperature of $50{ }^{\circ} \mathrm{C}$ and flow rate of 1.0 $\mathrm{ml} / \mathrm{min}$. Fig. 2 displays that the resulting chromatogram obtained from the HPLC. The two target peaks are clearly distinguished at 1.40 and $5.30 \mathrm{~min}$, respectively . The present HPLC-PDA analysis accomplished optimum separation in a short time without the need for a gradient system to improve the separation and pre-column washing after an analysis.

Table 1. Physical/chemical specifications of the $\mathrm{C} 1$ columns $^{\mathrm{a}}$ used and chromatographic ICP and 6CA separations obtained under the HPLC conditions examined ${ }^{\mathrm{b}}$

\begin{tabular}{|c|c|c|c|c|c|c|c|}
\hline \multirow{2}{*}{ Column, Trade name } & $d_{\mathrm{p}}$ & $\begin{array}{c}\text { Pore } \\
\text { diameter }\end{array}$ & $\begin{array}{c}\text { Pore } \\
\text { volume }\end{array}$ & $\begin{array}{c}\text { Surface } \\
\text { area }\end{array}$ & $\begin{array}{c}\text { Carbon } \\
\text { load }\end{array}$ & \multicolumn{2}{|c|}{ Chromatographic target peaks } \\
\hline & $(\mu \mathrm{m})$ & $(\mathrm{nm})$ & $(\mathrm{ml} / \mathrm{g})$ & $\left(\mathrm{m}^{2} / \mathrm{g}\right)$ & $(\%)$ & $\begin{array}{l}\text { Elution \& } \\
\text { Separation }\end{array}$ & Peak form \\
\hline (A) Developsil TMS-5 & 5 & 14 & 1.15 & 300 & 4.5 & Not eluted $^{c}$ & \\
\hline (B) Developsil TMS-3 & 3 & 14 & 1.15 & 300 & 4.5 & Not eluted & \\
\hline $\begin{array}{l}\text { (C) Daisopak SP-200-3- } \\
\text { C1-P }\end{array}$ & 3 & 20 & 1.1 & 300 & 3 & $\begin{array}{l}\text { Eluted \& } \\
\text { Separated }\end{array}$ & Sharp \\
\hline (D) Inertsil TMS & 5 & 10 & 1.05 & 450 & 3.5 & No ICP was eluted & \\
\hline (E) Wakosil 5TMS & 5 & 12 & $\mathrm{Nd}^{\mathrm{d}}$ & $\mathrm{Nd}$ & 4 & $\begin{array}{l}\text { Eluted \& } \\
\text { Separated } \\
\end{array}$ & Broadening \\
\hline
\end{tabular}

a i.d.= $4.6 \mathrm{~mm}$; length $=150 \mathrm{~mm}$.

${ }^{\mathrm{b}}$ Isocratic mobile phase of water; flow-rates $\geq 0.75 \mathrm{ml} / \mathrm{min}$; column temperatures $\geq 25{ }^{\circ} \mathrm{C}$; HPLC retention times $\leq 10 \mathrm{~min}$.

${ }^{\mathrm{c}}$ The column was difficult to elute 6CA and ICP peaks within $10 \mathrm{~min}$ (= the HPLC measuring time examined).

${ }^{\mathrm{d}}$ No data.

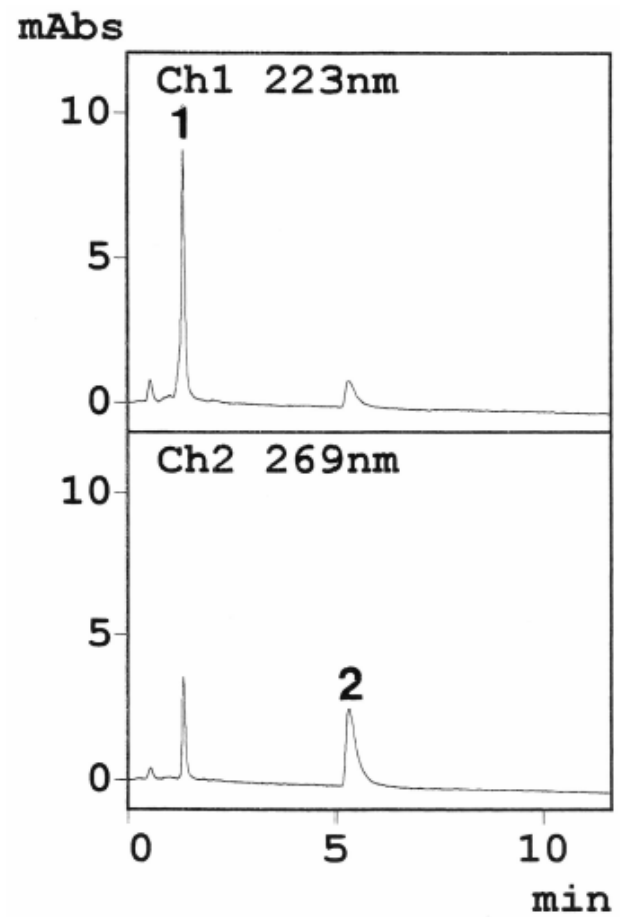

Fig. 2. Typical chromatograms of a standard mixture $(0.5 \mu \mathrm{g} / \mathrm{ml})$ obtained from the HPLC system. PDA detector set at $223 \mathrm{~nm}(\mathrm{Ch} 1)$ or $269 \mathrm{~nm}(\mathrm{Ch} \mathrm{2)}$. The injection volume was $15 \mu \mathrm{l}$. Peaks, $1=$ $6 \mathrm{CA}$ (retention time, $\mathrm{Rt}=1.40 \mathrm{~min}) ; 2=\mathrm{ICP}(\mathrm{Rt}=5.30 \mathrm{~min})$ 


\subsection{HPLC validation}

Table 2 summarizes the validation data for the performance parameters. The linearity and system suitability values were well within the international acceptance criteria. ${ }^{10}$

Table 2. Chromatographic method validation data

\begin{tabular}{lccc}
\hline & $6^{2} A^{\mathrm{a}}$ & ICP $^{\mathrm{b}}$ & Acceptance criterion $^{\mathrm{c}}$ \\
\hline Linearity $(r)^{\mathrm{d}}$ & 0.9997 & 0.9994 & $\geq 0.999$ \\
Range $(\mu \mathrm{g} / \mathrm{ml})$ & \multicolumn{2}{c}{$0.03-10$} & \\
Detection limit $^{\mathrm{e}}(\mu \mathrm{g} / \mathrm{ml})$ & 0.005 & 0.018 &
\end{tabular}

System suitability :

\begin{tabular}{lccc} 
a) Resolution (Rs) & \multicolumn{2}{c}{5.7} & $>2$ \\
b) Injection repeatability ${ }^{\mathrm{f}}(\mathrm{RSD}, \%)$ & & & \\
Retentiontime & 0.21 & 0.28 & $\leq 1$ \\
Peak area & 0.25 & 0.42 & $\leq 1$ \\
\hline
\end{tabular}

a PDA detector set at $223 \mathrm{~nm}$.

${ }^{\mathrm{b}}$ PDA detector set at $269 \mathrm{~nm}$.

${ }^{\mathrm{c}}$ Recommendations in the FDA guidelines. ${ }^{10}$

${ }^{\mathrm{d}} r$ is the correlation coefficient $(\mathrm{p}<0.01)$ for calibration curve.

${ }^{\mathrm{e}}$ Detection limit as the concentration of analyte giving a signal-to-noise ratio $=3$.

${ }_{\mathrm{f}}^{\mathrm{f}}$ Data as the relative standard deviations calculated for 10 replicate injections $(10 \mu \mathrm{l})$

of a mixed standard solution $(0.5 \mu \mathrm{g} / \mathrm{ml}$ of ICP and 6CA, respectively).

\section{Conclusions}

In the present study, a harmless HPLC-PDA method for detecting ICP and it metabolite 6CA using an isocratic $100 \%$ water mobile phase has been successfully established. The water mobile phase method is harmlessness to the environment and to humans and has a short run time and high system suitability. The HPLC system may be proposed as an international harmonized method for detecting ICP and 6CA. For the quantification in animal-derived foods, the proposed HPLC method will be applicable enough by performing a suitable sample preparation technique.

\section{Experimental}

\subsection{Chemicals, Reagents, and Equipment}

Standards of imidacloprid (ICP) and 6-chloronicotinic acid (6CA) (6-chloropyridine-3-carboxylic acid) and distilled water (HPLC grade) were purchased from Wako Pure Chem. Ltd. (Osaka, Japan).

The HPLC system, used for method development, included a model PU-980 pump and DG-980 50degasser (Jasco Corp., Tokyo, Japan) equipped with a model CO-810 column oven (Thosoh Corp., Tokyo, Japan), as well as a model SPD-M10A VP photodiode-array (PDA) detector (Shimadzu Scientific Instruments, Kyoto, Japan).

The following five types of C1 non-polar sorbent columns ( 3 or $5 \mu \mathrm{m} \mathrm{dP}$; $4.6 \mathrm{~mm}$ i.d.; $150 \mathrm{~mm}$ length) for HPLC analysis were used: Developsil ${ }^{\circledR}$ TMS-5 (or -3) (Nomura Chemical Co., Ltd., Aichi, Japan); Daisopak ${ }^{\circledR}$ SP-200-3-C1-P (Daiso Co., Ltd., Osaka, Japan); Inertsil ${ }^{\circledR}$ TMS (GL Sciences, Tokyo, Japan); Wakosil ${ }^{\circledR}$ 5TMS (Wako). Table 1 lists the particle physical specifications.

\subsection{Operating conditions}

The analytical column was a Daisopak SP-200-3-C1-P $(150 \times 4.6 \mathrm{~mm}, 3 \mu \mathrm{m})$ column using an isocratic mobile phase of water at a flow rate of $1.0 \mathrm{ml} / \mathrm{min}$ at $50{ }^{\circ} \mathrm{C}$. PDA detector was operated at 
$190-320 \mathrm{~nm}$ : the monitoring wavelengths were adjusted to 223 and $269 \mathrm{~nm}$ which represent maximums for 6CA and ICP, respectively. The injection volumes were $10-20 \mu \mathrm{l}$.

\subsection{Preparation of Stock Standards and Working Mixed Solutions}

Stock standard solutions of ICP and 6CA were prepared by dissolving each compound in water followed by water to a concentration of $20 \mu \mathrm{g} / \mathrm{ml}$. Working mixed standard solutions of these two compounds were prepared by suitably diluting the stock solutions with water. These solutions were kept in a refrigerator $\left(5^{\circ} \mathrm{C}\right)$.

\subsection{HPLC Validation}

\subsubsection{Linearity}

The calibration curve was generated by plotting peak areas ranging from 0.03 to $10 \mu \mathrm{g} / \mathrm{ml}$ versus their concentrations. The linearity was assessed from the linear regression with its correlation coefficient.

\subsubsection{Detection limit}

The detection limit should correspond to the concentration for which the signal-to-noise ratio. The value was defined as the lowest concentration level resulting in a peak area of three times the baseline noise.

\subsubsection{System suitability test}

The HPLC system suitability is an essential parameter of HPLC determination, and it ascertains the strictness of the system used. The suitability was evaluated as the relative standard deviations of peak areas and retention times calculated for 10 replicate injections of a mixed standard solution $(0.5$ $\mu \mathrm{g} / \mathrm{ml})$.

\section{References}

1 European Food Safety Authority (2013) EFSA assesses potential link between two neonicotinoids and developmental neurotoxicity. Press release 17 December 2013. Available on the internet. URL, http://www.efsa.europa.eu/en/press/news/131217.htm

2 WHO/FAO (2001) Joint Meeting on Pesticide Residues on Imidacloprid. Available on the internet. URL, http://apps.who.int/pesticide-residues-jmpr-database/pesticide?name=IMIDACLOPRID

3 Codex Alimentarius, Pesticide Residues in Food and Feed: 206 Imidacloprid, Maximum Residue Limits for Imidacloprid. Available on the internet. URL, http://www.codexalimentarius.net/pestres/data/pesticides/details.html?id=206

4 Watanabe E. (2012) Review on Current Analytical Methods with Chromatographic and Nonchromatographic Techniques for New Generation Insecticide Neonicotinoids (Chapter 22), Insecticides - Advances in Integrated Pest Management, Perveen, F. (Ed.), InTech. Available on the internet. URL, http://cdn.intechopen.com/pdfs-wm/25688.pdf

5 Kavvalakis M.P., Tzatzarakis M.N., Theodoropoulou E.P., Barbounis E.G., Tsakalof A.K., Tsatsakis A.M. (2013) Development and application of LC-APCI-MS method for biomonitoring of animal and human exposure to imidacloprid. Chemosphere, 93, 2612-2620.

6 Kamel A. (2010) Refined methodology for the determination of neonicotinoid pesticides and their metabolites in honey bees and bee products by liquid chromatography-tandem mass spectrometry (LC-MS/MS). J. Agric. Food Chem., 58, 5926-5931.

7 EU classification (The Dangerous Substances Directive 67/548/EEC), Council Directive 67/548/EEC 
of 27 June 1967 on the approximation of laws, regulations and administrative provisions relating to the classification, packaging and labelling of dangerous substances.

8 Anastas P.T., Warner J.C. (1998) Green Chemistry: Theory and Practice, Oxford University Press, Oxford, United Kingdom.

9 Yoshimura T., Nishinomiya T. et al. (2000) Green Chemistry: Aim for the Zero Emission-Chemicals, Sankyo Publishing Co. Ltd. Press, Tokyo, Japan.

10 FDA. Reviewer Guidance, Validation of Chromatographic Methods, Center for Drug Evaluation and Research (CFDER) 1994. 